\section{Imaging of a rare case of Bochdalek hernia in an adult female}

\section{Bahjat Barakat, ${ }^{1}$ Antonio Bruno, ${ }^{2}$ Lucia Calculli, ${ }^{2}$ Raffaele Pezzilli ${ }^{3}$}

'Department of Emergency; ${ }^{2}$ Department of Diagnostic Medicine and Prevention; ${ }^{3}$ Department of Digestive System, S. Orsola-Malpighi University Hospital, Bologna, Italy

Small bowel obstruction is usually seen in emergency room and represents at least 15\% of hospital admissions. ${ }^{1}$ It occurs when the flow of intraluminal contents is interrupted. We are able to distinguish two main forms of intestinal obstruction: functional due to altered intestinal physiology or mechanical. In advanced stage, small bowel obstruction leads to bowel dilation and retention of fluid within the lumen proximal to the obstruction. If bowel dilation is excessive, or strangulation occurs, perfusion to the intestine can be compromised leading to necrosis or perforation, complications, which increase the mortality, associated with small bowel obstruction. Hernia represents about $2 \%$ of all mechanical small bowel obstruction. ${ }^{2}$ Sometimes the clinically presentation is challenging, especially in its early phases when clinical signs and symptoms are poor and overlap with other diseases. For this reason we believe that the imaging study of this case is worthy to be reported.

A 48 year-old female was admitted to our emergency room for persistent pain of 2 hours duration localized in the right lower abdomen radiated to the homolateral flank and associated with headache, nausea and vomiting. In the past the patient was operated of tonsillectomy and enucleation of uterin fibroma and suffered of migraine; she was not tolerant to nonsteroidal antinflammatory drugs and triptans. Physical examination showed an increase of pain at palpation in the right iliac fossa and no alterations of the cardiopulmonary system. She was afebrile, blood arterial pressure was $110 / 70 \mathrm{mmHg}$ and had a normal oxygen saturation. Blood analyses showed an increase of white blood cells $(12.140 \mathrm{mmc})$; renal and hepatic functions were both normal as well as serum human chorionic gonadotrophin concentrations. Transabdominal ultrasonograhy showed no alterations of the liver, spleen, pancreas and kidney; a dilated bowel loops without free abdominal fluid was also seen (Figure 1). Patients underwent $\mathrm{x}$-ray of the abdomen that showed a dilation of bowel and moderate gas retention without clear signs of intestinal obstruction (Figure 2) and the chest x-ray showed a raised left hemidiaphragm without densification of the lungs and the presence of intestine in the thorax (Figure 3). The patient was treated with analgesics and fluids but the pain worsened; thus, a computed tomography of the thorax and abdomen was carried out. This examination showed a dilated loop of the ileum and ascendent colon, the presence of descendent colon above the diaphragm and segmental atelectasis of the left lower lobe (Figure 4). The patient was operated and at laparoscopy a herniation and strangulation of the colon was found as well as the presence of left postero-lateral defect of diaphragm; the thoracic herniated colon was reduced in the abdominal cavity and the diaphragm was repaired. The patient was discharged after seven days with a final diagnosis of intestinal obstruction due to Bochdalek hernia and the chest x-ray was completely normal (Figure 5).

Bochdalek hernia is a rare condition in adult and account from 0.2 to $17 \%$ of all diaphragmatic hernias; ${ }^{3}$ the symptoms are clinically vague and patient may present chest pain or may describe symptoms related to gastrointestinal tract as in our case. ${ }^{4}$ Most importantly, the lack of awareness of this illness leads to an incorrect diagnosis in about $40 \%$ of cases. ${ }^{5}$ Both early diagnosis with proper imaging and prompt operative management lead to good results, as our case demonstrates. Finally, as in our case, the ultrasonography has been found also able to show bowel obstruction, ${ }^{6}$ but it does not rule out a clear definition of intestinal occlusion. ${ }^{7}$ Thus, computed tomography is the most accurate
Correspondence: Raffaele Pezzilli, Department of Digestive System, S. Orsola-Malpighi University Hospital, via Massarenti 9, 40138 Bologna, Italy. Tel: +39.051.6364148 - Fax: +39.051.6364148.

E-mail: raffaele.pezzilli@aosp.bo.it

Key words: Intestinal obstruction; Abdominal hernia; Ultrasonography; Computed tomography.

Conflict of interest: the authors declare no potential conflict of interest.

Received for publication: 12 January 2016. Revision received: 12 February 2016.

Accepted for publication: 13 February 2016.

This work is licensed under a Creative Commons Attribution 4.0 License (by-nc 4.0).

(O)Copyright B. Barakat et al., 2016

Licensee PAGEPress, Italy

Emergency Care Journal 2016; 12:5730

doi:10.4081/ecj.2016.5730

method able to confirm the presence of diaphragmatic herniation as well as the presence of intestine in the thorax and its localization as cause of intestinal occlusion ${ }^{8,9}$ and facilitating the best management of this condition. In our opinion, when patient had mild signs of intestinal occlusion as demonstrated by abdominal ultrasonography, a computed tomography examination should be carried out for a better evaluation.

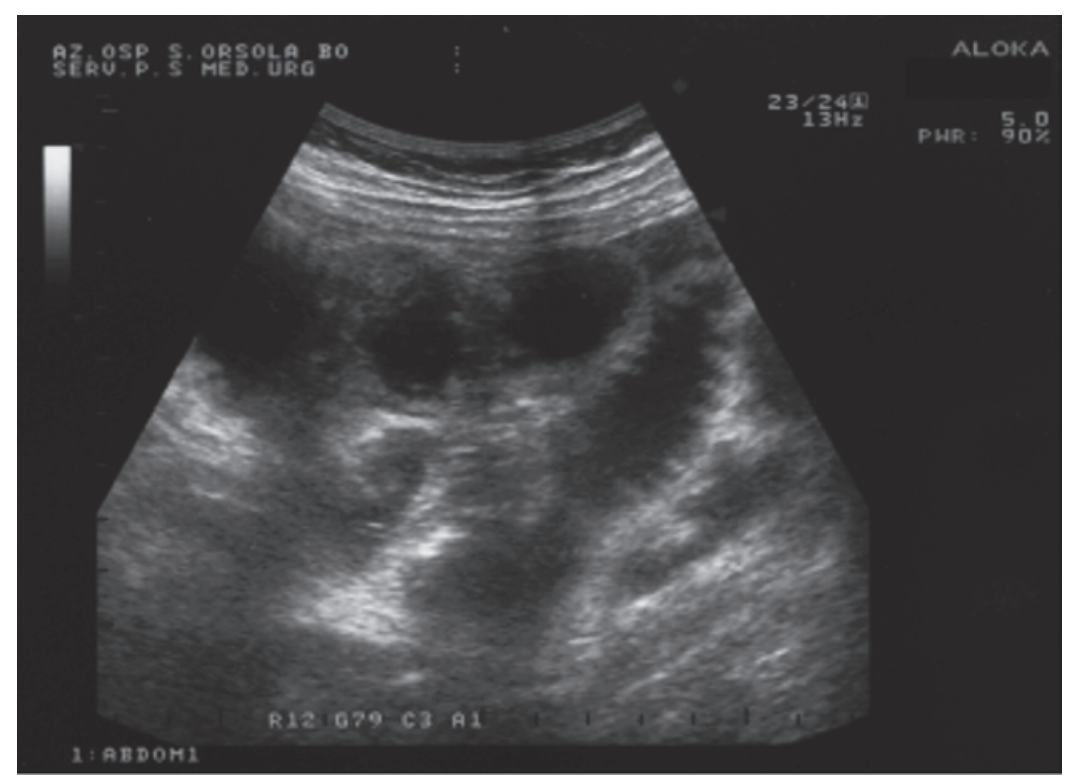

Figure 1. Transabdominal ultrasonography: dilation of small bowel loops associated with bowel wall thickness, presence of fluid-fluid levels and thickness of valvulae conniventes. 


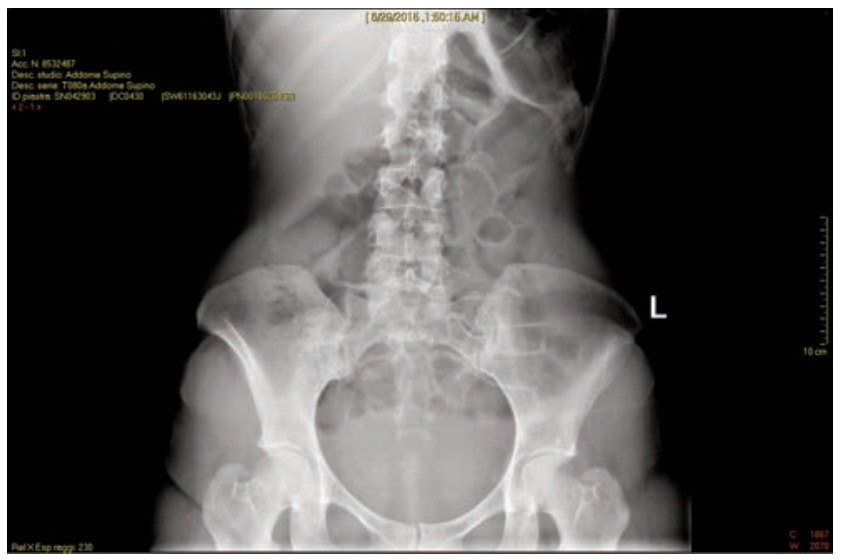

Figure 2. Plain $x$-ray of the abdomen: dilation of moderate gas retention without clear signs of intestinal obstruction.

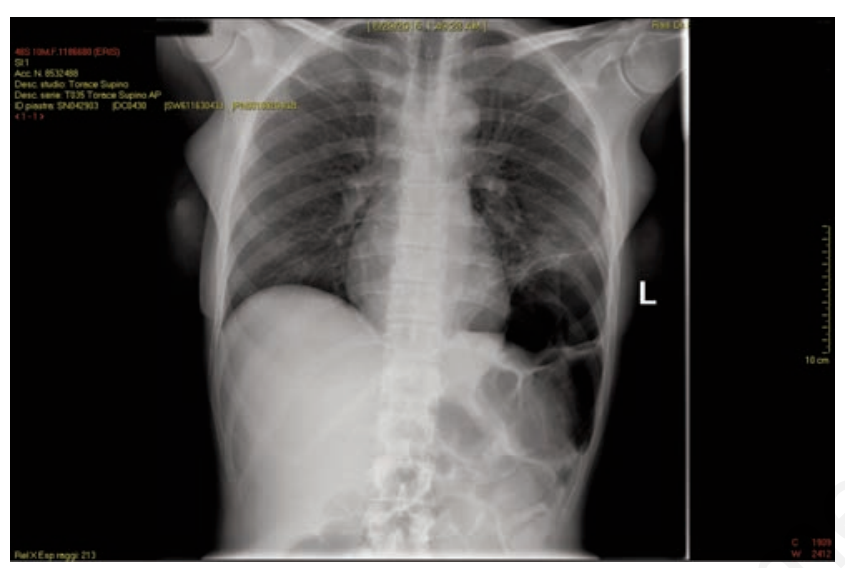

Figure 3. Chest $\mathrm{x}$-ray: suspected descendent colon herniation in left thorax.

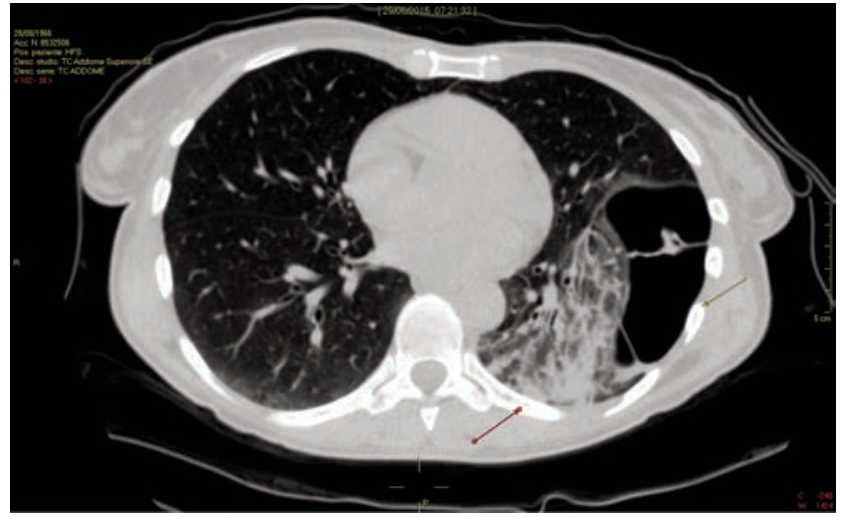

Figure 4. Computed tomography: herniation of the descendent colon in left thorax (yellow arrow) and segmental atelectasis of the left lower lobe (red arrow).

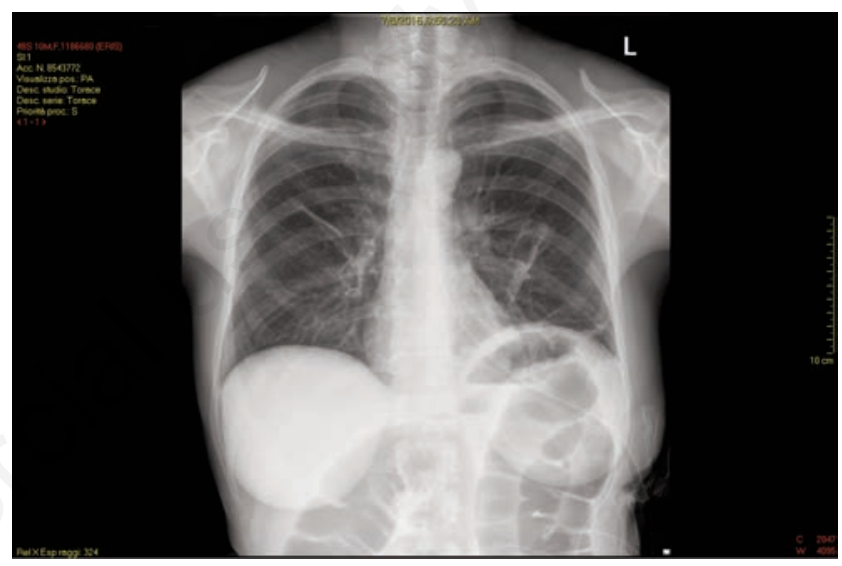

Figure 5. Chest $\mathrm{x}$-ray at discharge: completely normal.

\section{References}

1. Miller G, Boman J, Shrier I, Gordon PH. Natural history of patients with adhesive small bowel obstruction. Brit J Surg 2000;87:1240-7.

2. Miller G, Boman J, Shrier I, Gordon PH. Etiology of small bowel obstruction. Am J Surg 2000;180:33-6.

3. Alam WCA, Chander GCBN. Adult Bochdalek hernia. Med J Armed Forces
India 2005;61:284-6.

4. Mullins ME, Stein J, Saini SS, Mueller PR. Prevalence of incidental Bochdalek's hernia in a large adult population. Am J Roentgenol 2001;177:363-6.

5. Thomas S, Kapur B. Adult Bochdalek hernia: clinical features, management and results of treatment. Jpn J Surg 1991;21: 114-9.

6. Guttman J, Stone MB, Kimberly HH, Rempell JS. Point-of-care ultrasonography for the diagnosis of small bowel obstruc- tion in the emergency department. Can J Emerg Med Care 2015;17:206-9.

7. Mullins ME, Saini S. Imaging of incidental Bochdalek hernia. Semin Ultrasound CT 2005;26:28-36.

8. Shin MS, Mulligan SA, Baxley WA, Ho KJ. Bochdalek hernia of diaphragm in the adult. Diagnosis by computed tomography. Chest 1987;92:1098-101.

9. Wilbur AC, Gorodetsky A, Hibbeln JF. Imaging findings of adult Bochdalek hernias. Clin Imaging 1994;18:224-9. 